\title{
The significance of MDM2 SNP309 and p53 Arg72Pro in young women with breast cancer
}

\author{
ANNA LÅNG ${ }^{1}$, PIA PALMEBÄCK WEGMAN ${ }^{2}$ and STEN WINGREN ${ }^{1,2}$ \\ ${ }^{1}$ Institution of Clinical and Experimental Medicine, Division of Cell Biology, Faculty of Health Sciences, \\ Linköping University, 58185 Linköping; ${ }^{2}$ Department of Health and Medical Sciences, \\ Örebro University, 70182 Örebro, Sweden
}

Reeived March 24, 2009; Accepted May 8, 2009

DOI: $10.3892 /$ or_00000474

\begin{abstract}
The p53 protein and its regulator MDM2 is central to tumorigenesis by directing cells to undergo cell cycle arrest and/or apoptosis in response to DNA damage or other stress signals. The genes encoding these proteins contain nucleotide variation (p53 codon 72, MDM2 SNP309) that influences cellular response. We examined the p53 codon 72 and MDM2 SNP309 to determine their implication with age of disease onset and risk of breast cancer in young women ( $\leq 36$ years). No risk of breast cancer was observed for the genotypes of p53 and MDM2, however, a tendency $(\mathrm{P}=0.15)$ towards increased risk of early onset breast cancer was observed in carriers of two or more Pro and/or G alleles. We further calculated the influence on age at diagnosis. Cases were grouped according to the number of $\mathrm{G}$ and Pro alleles $(0,1,2$ or $3-4)$ and age at diagnosis. A significant trend towards decreased age at diagnosis with increased number of risk alleles was found $(\mathrm{P}=0.013)$. Our results suggest that $\mathrm{p} 53$ codon 72 and MDM2 SNP309 may be implicated in early onset breast cancer.
\end{abstract}

\section{Introduction}

Early onset breast cancer is a multifactorial disease, and the genesis and progression of most breast cancers are influenced by both environmental and genetic factors. A family history of breast cancer seems to be the greatest risk factor for early onset breast cancer, and the risk is a function of the number of affected relatives, the degree of relationship, and the time of onset (1). The most well-known genetic factors implicated in breast cancer are germ-line mutations in BRCAl and $B R C A 2$ (2,3). However, only a small section of patients have the disease as a consequence of hereditary mutations in one of these genes, and the origin of the vast majority of early

Correspondence to: Dr Sten Wingren, Department of Health and Medical Sciences, Örebro University, 70182 Örebro, Sweden E-mail: sten.wingren@orebroll.se

Key words: breast cancer, early onset, age of onset, polymorphism, p53, MDM2, codon 72, SNP309 onset breast cancers is still unknown. Naturally occurring variations in genes implicated in crucial processes such as apoptosis, DNA repair and proliferation may be modifiers of breast cancer risk.

The p53 protein and its regulator MDM2 are central to tumorigenesis by directing cells to undergo cell cycle arrest and/or apoptosis in response to DNA damage or other stress signals (4-6). The p53 gene harbours a polymorphism (G/C) in codon 72 that results in a substitution of arginine to proline (7) and it has been shown that the arginine allele induces a higher degree of apoptosis compared with the proline allele (8). In addition, the proline allele is more prone to induce increased levels of G1 arrest $(9,10)$. Studies of codon 72 with correlation to breast cancer risk and survival rates have shown contradictory results in different populations (11-15). The MDM2 protein contains a binding domain for p53 and attenuates its growth regulatory functions (16-18). One mechanism by which the MDM2 can impede tumor suppressor activity of p53 involves ubiquitin degradation by the proteasome pathway, resulting from the E3 ligase activity of MDM2 (19-22). In addition, p53 up-regulates the expression of MDM2 mRNA and protein, which subsequently inhibits p53 activity, thus forming a negative feedback loop $(18,23)$. Bond et al (24) identified a $\mathrm{T} \rightarrow \mathrm{G}$ substitution in the $\mathrm{P} 2$ promoter of the MDM2 gene (SNP309), which is associated with higher affinity for the transcription factor $\mathrm{Sp} 1$. This single nucleotide polymorphism leads to increased MDM2 mRNA and protein levels and consequently p53 inhibition. Adding to this, there is a tendency showing earlier cancer onset in certain groups of patients harbouring the $\mathrm{G} / \mathrm{G}$ or $\mathrm{T} / \mathrm{G}$ genotype for MDM2 SNP309 (24,25).

In the present case-control study we investigated polymorphisms in $M D M 2$ and p53 and the risk of early onset breast cancer. In addition, since previous studies have shown that younger age groups develop cancer earlier when carrying a homozygote genotype, at least for the MDM2 SNP309, we also studied the allele influence on age at diagnosis.

\section{Materials and methods}

Study populations. The study included 123 young women diagnosed with breast cancer between the years 1980 and 1994 in the South-East Sweden Health Care Region. The patients had a median age of 34 years, raging from 24 to 36 
Table I. Genotype frequencies of the MDM2 SNP309 and $p 53$ codon 72 polymorphisms.

\begin{tabular}{|c|c|c|c|c|c|c|}
\hline & \multicolumn{3}{|c|}{ MDM2 SNP309 } & \multicolumn{3}{|c|}{ p53 codon 72} \\
\hline & $\mathrm{T} / \mathrm{T}$ & $\mathrm{T} / \mathrm{G}$ & $\mathrm{G} / \mathrm{G}$ & $\mathrm{Arg} / \mathrm{Arg}$ & Arg/Pro & Pro/Pro \\
\hline $\begin{array}{l}\text { Early onset breast } \\
\text { cancer }(\%)\end{array}$ & $52(42.3)$ & $57(46.3)$ & $14(11.4)$ & $65(56)$ & $45(38.8)$ & $6(5.2)$ \\
\hline Controls (\%) & 68 (46.6) & $60(41.1)$ & $18(12.3)$ & 79 (55.6) & $58(40.8)$ & $5(3.5)$ \\
\hline
\end{tabular}

years of age. Tissue samples from archival material were obtained from the pathology departments of hospitals in the South-East Sweden Health Care Region. The control group from the same geographic area consisted of 146 healthy female blood donors between 18-39 years of age with a median age of 30 years.

DNA extraction. DNA from blood donors was isolated using Wizard ${ }^{\circledR}$ SV Genomic DNA Purification System (Promega Corp., Madison, WI, USA). DNA from paraffin-embedded normal lymph node tissues of young breast cancer patients was extracted according to a standard protocol.

Polymerase chain reaction for MDM2 and p53. Amplification of the MDM2 SNP309 and $p 53$ codon 72 regions was performed using the following primers; forward, 5'-CGGGAGT TCAGGGTAAAGGT-3'; reverse, 5'-Biotin-TCGGAACGTG TCTGAACTTG-3' for MDM2 and forward, 5'-GAAGACCC AGGTCCAGATGA-3'; reverse, 5'-CTGCCCTGGTAGGTT TTCTG-3' for $\mathrm{p} 53$. The PCR reactions for MDM2 were carried out in a total volume of $30 \mu 1$, adding $60 \mathrm{ng}$ of DNA to the reaction mixture. p53 was amplified using $40 \mathrm{ng}$ of DNA in a total volume of $20 \mu 1$. The PCR reaction mixtures were composed of $1 \mathrm{X} \mathrm{MgCl}_{2}$ free PCR buffer, $2 \mathrm{mM} \mathrm{MgCl}$, $0.2 \mathrm{mM}$ dNTPs, $1 \mu \mathrm{M}$ each of forward and reverse primer, and 0.5-0.75 units of TaqDNA polymerase (Promega). An initial denaturation at $94^{\circ} \mathrm{C}$ for 3 min was followed by 35-40 cycles of denaturation at $94^{\circ} \mathrm{C}$ for $45 \mathrm{sec}$, annealing at 55$60^{\circ} \mathrm{C}$ for $45 \mathrm{sec}$ and elongation at $72^{\circ} \mathrm{C}$ for $45 \mathrm{sec}$. An elongation step of $5 \mathrm{~min}$ at $72^{\circ} \mathrm{C}$ followed the final cycle and the reactions were then kept at $4^{\circ} \mathrm{C}$. All PCR reactions were run on a PTC-200 Peltier Thermal Cycler DNA Engine (MJ Reaserch $^{\mathrm{TM}}$, Inc., Waltham, MA, USA).

Pyrosequencing. The genotypes of SNP309 were verified by pyrosequencing analysis with the sequencing primer 5'-CAG GGTAAAGGTCACG-3' (final concentration $0.3 \mu \mathrm{M}$ ) in an automated PSQ96 MA pyrosequencer instrument (Biotage AB, Uppsala, Sweden). Briefly, $25 \mu 1$ of the PCR products were immobilized on $3 \mu \mathrm{l}$ Streptavidin Sepharose ${ }^{\mathrm{TM}}$ High Performance beads (Amersham Biosciences AB, Uppsala, Sweden), followed by denaturation, washing, and primer annealing steps, using a vacuum device, according to the manufacturer's instructions (Biotage $\mathrm{AB}$ ). For all SNP runs, the Pyro Gold reagents kit (Biotage $A B$ ) was used and the sequencing was performed as previously described (26). The results were subsequently analysed with the pyrosequencing software PSQ96 MA 2.1 (Biotage AB). However, in 14 samples of the paraffin-embedded normal lymph node tissues of young breast cancer patients no results were obtained. Therefore, purified PCR products of these samples were applied to dideoxy sequencing analysis using isotope ${ }^{33} \mathrm{P}$, according to the Thermo Sequenase Radiolabeled Terminator Cycle Sequencing Kit (USB Corp., Cleveland, USA), and run on a polyacrylamide gel (6\% polyacrylamide, $8 \mathrm{M}$ Urea) under denaturating conditions. The gel was then dried and exposed on X-ray film (Kodac Biomax MS using Trans Screen LE intensifying screen) at $-70^{\circ} \mathrm{C}$.

Restriction fragment length polymorphism (RFLP). The p53 codon 72 polymorphism was detected using the restriction enzyme BstUI that recognises a restriction site on the Arg allele. Ten units of BstUI (New England Biolabs) and 1.6 $\mu 1$ NEBuffer 2 (supplied by the manufacturer) were added to $5 \mu 1$ of PCR products and incubated at $60^{\circ} \mathrm{C}$ for $5 \mathrm{~h}$. After digestion, fragments were resolved by electrophoresis on a $3 \%(\mathrm{w} / \mathrm{v})$ agarose gel containing $1 \mathrm{X}$ TBE buffer and ethidium bromide $(0.5 \mu \mathrm{g} / \mu \mathrm{l})$.

P53 status. Mutations in exon 5-8, loss of heterozygosity as well as protein expression of the p53 gene has been described earlier (27). Briefly, single strand conformational polymorphism (SSCP) was used to screen for mutations in the p53 gene and tumors showing mobility shifts were collected from the gel and sequenced using incorporation of $\left[\alpha^{3} \mathrm{P}\right]$ dATP. Loss of heterozygosity was estimated by means of an intragenic microsatellite marker. $\alpha$-dATP ${ }^{32}$ was incorporated by PCR and amplicons were separated on a denaturating polyacrylamide gel. The signal intensity was then compared between bands of tumor and normal cell origin. For immunohistochemistry, $5 \mu \mathrm{m}$ tumor sections were deparaffinised and rehydrated before antigen retrieval in microwave oven. Tissue sections were incubated with the monoclonal antibody DO-7 that was coupled with the avidin-biotin-peroxidase complex. Finally, the p53 protein was stained by addition of 3,3'-diaminobenzidine and cells counterstained by Mayer's haematoxylin.

Statistical analysis. Odds ratios (OR) and 95\% confidence intervals (CI) were calculated by logistic regression to evaluate the risk of breast cancer for individuals homozygous or heterozygous for the Pro and $\mathrm{G}$ alleles in p53 codon 72 and MDM2, respectively. P-values were calculated by $\chi^{2}$ analysis. One-way analysis of variance (ANOVA) in the Statistical Package for the Social Sciences (SPSS) Advanced Models $^{\mathrm{TM}} 12.0$ software was used for comparing mean age at 
Table II. Calculated odds ratios (OR) of p53 codon 72 and MDM2 SNP309 for young breast cancer patients and controls.

\begin{tabular}{lcccc}
\hline Genotype & Controls & Cases & OR & 95\% CI \\
\hline MDM2 T/T & 68 & 52 & & \\
MDM2 T/G +G/G & 78 & 71 & 1.19 & $0.71-1.99$ \\
p53 Arg/Arg & 79 & 65 & & 0.48 \\
p53 Arg/Pro + Pro/Pro & 63 & 51 & 0.98 & $0.58-1.66$ \\
\hline
\end{tabular}

Table III. The distribution of p53 status. ${ }^{a}$

\begin{tabular}{|c|c|c|c|c|c|c|}
\hline & \multicolumn{2}{|c|}{ IHC } & \multicolumn{2}{|c|}{ Mutations } & \multicolumn{2}{|c|}{ LOH-status } \\
\hline & + & - & Mutation & wt & $\mathrm{LOH}$ & $\mathrm{ROH}$ \\
\hline \multicolumn{7}{|l|}{ Codon 72} \\
\hline Arg/Arg & 16 & 28 & 9 & 44 & 6 & 9 \\
\hline Arg/Pro & 20 & 15 & 6 & 35 & 8 & 12 \\
\hline Pro/Pro & 2 & 1 & 2 & 2 & 2 & 0 \\
\hline P-value & \multicolumn{2}{|c|}{0.23} & \multicolumn{2}{|l|}{0.20} & \multicolumn{2}{|c|}{0.24} \\
\hline \multicolumn{7}{|l|}{ SNP309 } \\
\hline $\mathrm{T} / \mathrm{T}$ & 17 & 20 & 6 & 38 & 7 & 6 \\
\hline $\mathrm{T} / \mathrm{G}$ & 18 & 25 & 9 & 39 & 6 & 14 \\
\hline $\mathrm{G} / \mathrm{G}$ & 5 & 3 & 4 & 8 & 2 & 5 \\
\hline P-value & \multicolumn{2}{|c|}{0.48} & \multicolumn{2}{|l|}{0.29} & \multicolumn{2}{|c|}{0.14} \\
\hline
\end{tabular}

aProtein expression estimated by immunohistochemistry, gene mutations and loss of heterozygosity according to $p 53$ and $M D M 2$ genotype.

diagnosis according to the number of alleles coding for Pro in codon 72 in the p53 gene and the number of $\mathrm{G}$ alleles in SNP309 in the MDM2 gene.

\section{Results}

The genotype frequencies of the MDM2 and p53 polymorphisms in the early onset breast cancer cases and controls are presented in Table I. Odds ratios were calculated according to genotypes of p53 and MDM2 but no risk of breast cancer was observed (Table II). The distribution of p53 status, i.e., protein expression estimated by immunohistochemistry, gene mutations and loss of heterozygosity according to genotype is shown in Table III. However, no significant trend was seen. We then grouped the material according to the number of risk alleles (Pro and G) in p53 codon 72 and MDM2 SNP309, respectively. Cases and controls with $<2$ Pro and $\mathrm{G}$ alleles were defined as a low risk group and those with $\geq 2$ alleles were grouped together and defined as high risk group. A tendency $(\mathrm{P}=0.15)$ towards increased risk of early onset breast cancer was observed among those with $\geq 2$ of the Pro and/or G alleles (Table IV).

We further calculated the influence of p53 and MDM2 on age at diagnosis. Breast cancer cases were grouped according to the number of $\mathrm{G}$ and Pro alleles $(0,1,2$ or $3-4)$ and age at
Table IV. Calculated odds ratio of the gene interaction between p53 codon 72 and MDM2 SNP309.

\begin{tabular}{lccccc}
$\begin{array}{l}\text { No. of risk } \\
\text { alleles }\end{array}$ & Controls & Cases & OR & $95 \%$ CI & P-value \\
\hline $0-1$ & 99 & 71 & & & \\
$\geq 2$ & 43 & 24 & 1.46 & $0.84-2.53$ & 0.15 \\
\hline
\end{tabular}

Patients were grouped according to the number of risk alleles (i.e., proline in codon 72 and $\mathrm{G}$ in SNP309).

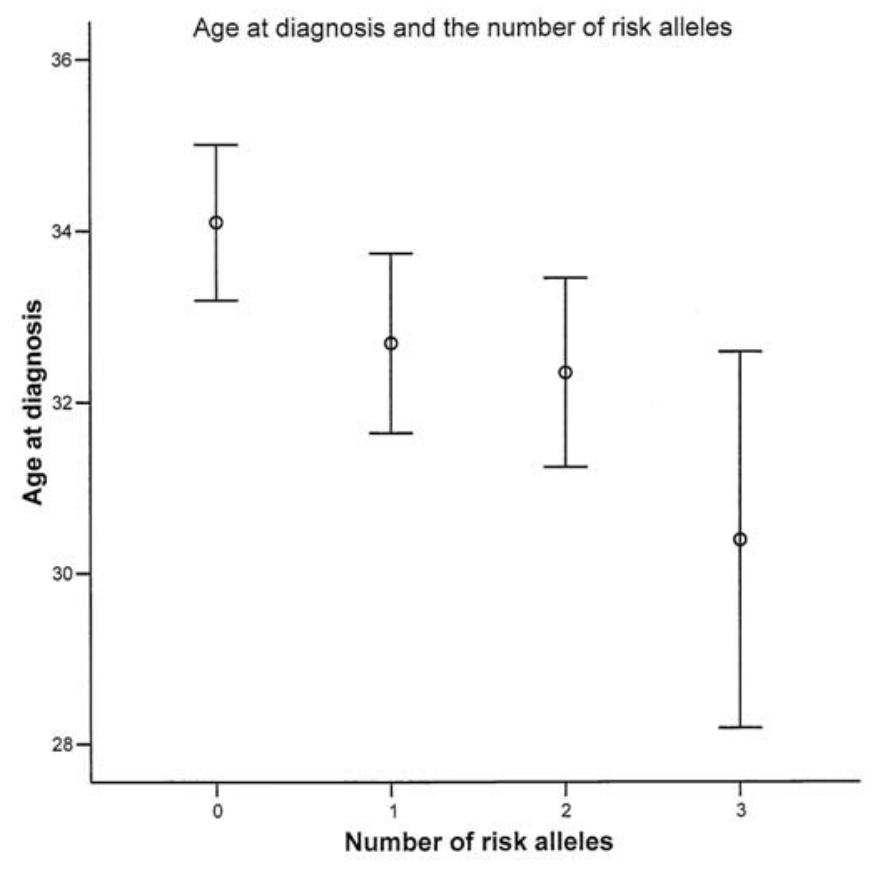

Figure 1. Mean age at breast cancer diagnosis was plotted against the number of risk alleles. A significant trend towards decreased age at diagnosis was found with increased number of risk alleles $(\mathrm{P}=0.013)$. Risk alleles are defined as having proline in codon 72 in the $p 53$ gene or G-allele in SNP309 of the MDM2 gene. The bars represent standard error of the mean. Difference in mean age according to risk alleles was tested using oneway analysis of variance (ANOVA).

diagnosis. The difference in mean age between groups was tested using one-way analysis of variance (ANOVA). Fig. 1 shows a significant trend towards decreased age at diagnosis with increased number of risk alleles $(\mathrm{P}=0.013)$. 


\section{Discussion}

In the present study we observed a significant trend towards a decreased age at diagnosis with increasing numbers of $p 53$ codon 72 Pro and MDM2 SNP309 G alleles. In addition, when using the control group and calculating the risk of breast cancer we found a weak association between risk and MDM2 SNP309 and $p 53$ codon 72.

Previous studies of combined analyses of both $p 53$ codon 72 and MDM2 SNP309 and the risk of breast cancer have generally shown lack of association. A report by Cox and collaborators (28), who genotyped participants of a nurse health study, demonstrated no association to breast cancer risk. Similar results were also shown in a pooled series of European cases and controls from 5 studies (29). However, in an Asian population it was reported that carriers of the MDM2 SNP309 G allele had an increased risk of both postmenopausal and familial breast cancer, although the p53 codon 72 alleles did not affect breast cancer risk (30). Nevertheless, in their younger age group ( $\leq 40$ years) results of both MDM2 SNP309 and p53 codon 72 polymorphisms were in accordance with our study of early onset cases (30). In investigations of familiar breast cancer, Tommiska et al (13) and Wilkening et al (31) studied the influence of codon 72 and SNP309, respectively, without finding any relationship to risk of familial breast cancer. On the other hand, Ohayon et al (32) showed that arginine homozygosity was associated with increased risk of familial breast cancer in Jewish women without the predominant Jewish mutations in BRCA1/BRCA2.

The polymorphisms in $p 53$ codon 72 and MDM2 SNP309 have been shown to influence age at onset, especially in hereditary cancers in several reports, but it is less significant in sporadic cancer. In a study of patients with the Li-Fraumeni syndrome, of which the majority depends on germline mutations in $p 53$, carriers of SNP309 $\mathrm{G}$ and codon 72Arg alleles were diseased significantly earlier (25). Ruijs and colleagues (33) studied the MDM2 SNP309 in $p 53$ germline mutation carriers and found in accordance with Bougeard et al (25) that the G allele was associated with early onset of tumor formation. High prevalence of somatic p53 mutations has been reported from head and neck squamous cell carcinoma. Nakashima et al (34) investigated this malignancy with respect to the impact of MDM2 SNP309 and age of onset and the average age at tumor onset was found to be significantly lower in the GG genotype.

In a recent study by Wilkening et al (35), including pooled data from 11 reports consisting of both familial and sporadic breast cancer cases, as well as patients with different ethnic origin, no association to earlier tumor formation was found for MDM2 SNP309. Wilkening and co-workers (31) also studied women with familial breast cancer without $B R C A 1$ and $B R C A 2$ mutations and the polymorphism of $M D M 2$ SNP309 did not seem to modify the age of onset in this population. However, the mutational status of BRCA1/BRCA2 might influence results since Yarden et al (36) found the opposite showing that the GG genotype of SNP309 was significantly associated with earlier diagnosis in AshkenaziJewish with $B R C A 1 / B R C A 2$ mutations. In a Chinese breast cancer population, including both sporadic and familial breast cancer cases, Lum et al (30) found a significant associ- ation between SNP309 T genotype and early age at cancer diagnosis.

The present knowledge of MDM2 SNP309 and p53 codon 72 indicates that its implication in carcinogenesis may be dependent on mutational status of genes in the p53 pathway as shown in studies of the Li-Fraumeni syndrome and BRCAX mutational carriers. This hypothesis is partly strengthened by the present investigation. $p 53$ mutation was a minor event in our study population but overexpression of the p53 protein occurred in almost half of cases indicating a possible dysregulation of the protein. Family history and the status of $B R C A 1 / B R C A 2$ genes in the present cohort is unknown since cases were selected from a time period with little focus on hereditary disease, however, a family history of breast cancer and mutations of $B R C A 1 / B R C A 2$ is more common in younger patients compared to the elder counterparts. Nevertheless, our results suggest that polymorphisms in p53 codon 72 and MDM2 SNP309 may be implicated in breast cancer of young women.

\section{Acknowledgements}

This study was supported by grants from the Swedish Cancer and Allergy Society, the Swedish Cancer Society, Gunnar Nilsson Cancer Foundation and Percy Falks Cancer Foundation.

\section{References}

1. Collaborative Group on Hormonal Factors in Breast Cancer: Familial breast cancer: collaborative reanalysis of individual data from 52 epidemiological studies including 58.209 women with breast cancer and 101.986 women without the disease. Lancet 358: 1389-1399, 2001.

2. Miki Y, Swense J, Shattuck-Eidens D, et al: A strong candidate for the breast and ovarian cancer susceptibility gene BRCAl. Science 266: 66-71,1994.

3. Wooster R, Bignell G, Lancaster J, et al: Identification of the breast cancer susceptibility gene BRCA2. Nature 378: 789-792, 1995.

4. Slee EA, O'Connor DJ and Lu X: To die or not to die: how does p53 decide? Oncogene 23: 2809-2818, 2004.

5. Vousden KH and Lu X: Live or let die: the cell's response to p53. Nat Rev Cancer 2: 594-604, 2002.

6. Sionov RV and Haupt Y: The cellular response to p53: the decision between life and death. Oncogene 18: 6145-6157, 1999.

7. Matlashewski GJ, Tuck S, Pim D, Lamb P, Schneider J and Crawford LV: Primary structure polymorphism at amino acid residue 72 of human p53. Mol Cell Biol 7: 961-963, 1987.

8. Dumont P, Leu JI, Della Pietra AC III, George DL and Murphy M: The codon 72 polymorphic variants of $p 53$ have markedly different apoptotic potential. Nat Genet 33: 357-365, 2003.

9. Pim D and Banks L: p53 polymorphic variants at codon 72 exert different effects on cell cycle progression. Int J Cancer 108: 196-199, 2004.

10. Sullivan A, Sved N, Gasco M, et al: Polymorphism in wild-type p53 modulates response to chemotherapy in vitro and in vivo. Oncogene 23: 3328-3337, 2004.

11. Papadakis EN, Dokianakis DN and Spandidos DA: P53 codon 72 polymorphism as a risk factor in the development of breast cancer. Mol Cell Biol Res Commun 3: 389-392, 2000.

12. Bonafé M, Ceccarelli C, Farabegoli F, et al: Retention of the p53 codon 72 arginine allele is associated with a reduction of disease-free and overall survival in arginine/proline heterozygous breast cancer patients. Clin Cancer Res 9: 4860-4864, 2003.

13. Tommiska J, Eeorola H, Heinonen M, et al: Breast cancer patients with $p 53$ Pro72 homozygous genotype have a poorer survival. Clin Cancer Res 11: 5098-5103, 2005. 
14. Noma C, Miyoshi Y, Taqushi T, Tamaki Y and Noquchi S: Association of $p 53$ genetic polymorphism (Arg72Pro) with estrogen receptor positive breast cancer risk in Japanese women. Cancer Lett 210: 197-203, 2004.

15. Mabrouk I, Baccouche S, El-Abed R, et al: No evidence of correlation between $p 53$ codon 72 polymorphism and bladder or breast carcinoma in Tunisian patients. Ann NY Acad Sci 1010: 764-770, 2003.

16. Chen J, Wu X, Lin J and Levine AJ: MDM-2 inhibits the $\mathrm{G}_{1}$ arrest and apoptosis functions of the p53 tumor suppressor protein. Mol Cell Biol 16: 2445-2452, 1996.

17. Momand J, Zambetti GP, Olson DC, George D and Levine AJ: The $M D M-2$ oncogene product forms a complex with the p53 protein and inhibits p53-mediated transactivation. Cell 69: $1237-1245,1992$.

18. Wu X, Bayle JH, Olson D and Levine AJ: The p53-mdm-2 autoregulatory feedback loop. Genes Dev 7: 1126-1132, 1993

19. Kubbutat MH, Jones SN and Vousden KH: Regulation of p53 stability by Mdm2. Nature 387: 299-303, 1997.

20. Haupt Y, Maya R, Kazaz A and Oren M: MDM2 promotes the rapid degradation of p53. Nature 387: 296-299, 1997.

21. Fang S, Jensen JP, Ludwig RL, Vousden KH and Weissman AM: MDM2 is a RING finger-dependent ubiquitin protein ligase for itself and p53. J Biol Chem 275: 8945-8951, 2000.

22. Honda R, Tanaka H and Yasada H: Oncoprotein MDM2 is a ubiquitin ligase E3 for tumor suppressor p53. FEBS Lett 420: 25-27, 1997.

23. Barak Y, Juven T, Haffner R and Oren M: MDM2 expression is induced by wild-type p53 activity. EMBO J 12: 461-468, 1993.

24. Bond GL, Hu W, Bond EE, et al: A single nucleotide polymorphism in the $M D M 2$ promoter attenuates the p53 tumor suppressor pathway and accelerates tumor formation in humans. Cell 119: 591-602, 2004.

25. Bougeard G, Baert-Desurmont S, Tournier I, et al: Impact of the MDM2 SNP309 and TP53 Arg72Pro polymorphism on age of tumour onset in Li-Fraumeni syndrome. J Med Genet 43: 531-533, 2006.

26. Ahmadian A, Ehn M and Hober S: Pyrosequencing: history, biochemistry and future. Clin Chim Acta 363: 83-94, 2006.
27. Gentile M, Bergman Jungestrom M, Olsen KE, Söderkvist P and Wingren S: p53 and survival in early onset breast cancer: analysis of gene mutations, loss of heterozygosity and protein accumulation. Eur J Cancer 35: 1202-1207, 1999.

28. Cox DG, Deer D, Guo Q, Tworoger SS, Hankinson SE, Hunter DJ and De Vivo I: The p53 Arg72Pro and MDM2-309 polymorphisms and risk of breast cancer in the nurses health studies. Cancer Causes Control 18: 621-625, 2007.

29. Schmidt M, Reincke S, Broeks A, et al: Do MDM 2 and TP53 $\mathrm{R} 73 \mathrm{P}$ interact in breast cancer susceptibility? A large pooled series from breast cancer association consortium. Cancer Res 67: 9584-9590, 2007.

30. Lum S, Chua H, Li H, Rao N, Wei J, Shao Z and Sabapathy K: MDM2 SNP309 allele increases risk but the T allele is associated with earlier onset age of sporadic breast cancer in the Chinese population. Carcinogenesis 29: 754-761, 2008.

31. Wilkening S, Bermejo JL, Burwinkel B, et al: The single nucleotide polymorphism IVS1+309 in mouse double minute 2 does not affect risk of familial breast cancer. Cancer Res 66: 646-648, 2006.

32. Ohayon T, Gershoni-Baruch R, Papa MZ, DistelmanMenachem T, Eisenberg-Barzilia S and Friedman E: The R72P P53 mutation is associated with familial breast cancer in Jewish women. Br J Cancer 92: 1144-1148, 2005.

33. Ruijs MW, Schidt MK, Nevanlinna H, et al: The singlenucleotide polymorphism 309 in the MDM2 gene contributes to the Li-Fraumeni syndrome and related phenotypes. Eur J Human Genet 15: 110-114, 2007.

34. Nakashima M, Kondo S, Shimizu Y, Wakisaka N, Murono S, Furukawa $\mathrm{M}$ and Yoshizaki T: Impact of $M D M 2$ single nucleotide polymorphism on tumour onset in head and neck squamous cell carcinomas. Acta Otolaryngol 128: 808-813, 2008.

35. Wilkening S, Bermejo J and Hemminki K: MDM2 SNP 309 and cancer risk: a combined analysis. Carcinogenesis 28: 2262-2267, 2007.

36. Yarden RI, Friedman E, Metsuyanim S, Olender T, Ben-Asher E and Papa MZ: MDM2 SNP309 accelerates breast and ovarian carcinogenesis in BRCA1 and BRCA2 carriers of JewishAshkenazi descent. Breast Cancer Res Treat 111: 497-504, 2008 